\title{
Recommendations for Neuroradiology Training during Radiology Residency by the American Society of Neuroradiology Section Chiefs Leadership Group
}

\author{
(D) M. Wintermark, (D). Anderson, (D)V. Gupta, (D)T.A. Kennedy, (D).A. Loevner, (D)R.F. Riascos, (D). Robson, (D) G. Saigal, and \\ (D) C. Glastonbury
}

$\mathbf{T}$ he American Society of Neuroradiology [ASNR] Section Chiefs Leadership Group strongly feels that residency education in neuroradiology should become more standardized and wishes to make recommendations and facilitate the ability of residency programs to educate and train their residents in neuroradiology.

\section{Background}

Various changes to Accreditation Council for Graduate Medical Education (ACGME) radiology residency programs have resulted in a highly variable amount and type of exposure to neuroradiology cases and education. These include, but are not limited to, the advent of the IR residency and ESIR training, potentially limiting the number of rotations by the IR residents to neuroradiology, increased reliance on overnight and float rotations that may have significant neuroimaging exposure but are staffed by non-neuroradiologists, and specialized curricula or mini-fellowships in nonneuroradiology areas in the R4/PGY5 year that may limit the exposure to the expertise of neuroradiologists and neuroimaging. Additionally, the structure of the current ABR certification process, though allowing testing for routine competency with the Core Examination, does not necessarily ensure that there is continued learning and growth, because the individual can opt out of the neuroradiology modules.

From the Department of Radiology (M.W.), Neuroradiology Section, Stanford University and Healthcare, Stanford, California; Department of Radiology (J.A.), Neuroradiology Section, Oregon Health and Science University, Portland, Oregon; Department of Radiology (V.G.), Division of Neuroradiology, Mayo Clinic, Jacksonville, Florida; Department of Radiology, Division of Neuroradiology (T.A.K.), University of Wisconsin School of Medicine and Public Health, Madison, Wisconsin; Department of Radiology (L.A.L.), Division of Neuroradiology, University of Pennsylvania Health System, Philadelphia, Pennsylvania; Department of Diagnostic and Interventional Imaging (R.F.R.), Division of Neuroradiology, University of Texas Health Houston, Houston, Texas; Department of Radiology (C.R.), Neuroradiology Division, Boston Children's Hospital, Harvard Medical School, Boston, Massachusetts; Department of Radiology (G.S.), Neuroradiology Section, University of Miami Miller School of Medicine, Miami, Florida; and Department of Radiology and Biomedical Imaging (C.G.), Neuroradiology Section, University of California, San Francisco, San Francisco, California.

Please address correspondence to Max Wintermark, MD, Stanford University, Department of Radiology, Neuroradiology Division, 300 Pasteur Dr, Room S047, Stanford, CA 94305-5105; e-mail: max.wintermark@gmail.com

- Indicates open access to non-subscribers at www.ajnr.org

http://dx.doi.org/10.3174/ajnr.A6968
Thus, the ASNR Section Chiefs Leadership Group has made the following recommendations:

\section{Exposure}

- It is strongly recommended that radiology trainees have at least 16-24 weeks of training in neuroradiology under the direction of a neuroradiologist. Additionally, it is recommended that at least 8-12 of those weeks occur during the last 3 years of their training before they start practicing independently.

- Continued exposure and education in neuroimaging is needed to maintain skills developed during the early years of residency. The neuroradiology training during residency should be modeled on the neuroradiology curriculum developed by ASNR (https://www.asnr.org/education/ neuroradiology-curricula-for-trainees/).

- It is strongly recommended that radiology trainees have at least 60 hours of dedicated instruction in neuroimaging. Additionally, it is recommended that at least 30 of those hours occur during the last 3 years of their training before they start practicing independently.

- It is strongly recommended that residents be exposed to educational activities including lectures and other didactic education by faculty at the institution/program. In addition, it is recommended that online resources such as (but not limited to) those made available by ASNR (https://www.asnr.org/ education/fellowship-portal/educational-resources) be used during residency training.

\section{Experience}

- It is strongly recommended that radiology trainees interpret a variety of neuroimaging studies throughout their training.

- Continued interpretation and education in brain, spine, head \& neck, and neurovascular imaging should occur throughout the residency. Although specific numbers of cases are not an indication of competency, a guideline for consideration is that a radiology trainee interpret at least 300 neuroimaging CT scans, 150 Neuroimaging MRI scans, and 50 neurovascular imaging studies (neuro CTAs and neuro MRAs) under the guidance and direction of a neuroradiologist during the last 3 years of their training, before he or she starts practicing independently. 
- It is important to read a significant number and variety of neuroimaging cases and although we understand the value of float and call type experiences for neuroimaging, the fundamental aspects of routine neuroimaging are felt to be best done under the direction and guidance of dedicated neuroradiologists, even if the feedback from the neuroradiologists may not be in real-time.

\section{Competency}

- It is strongly recommended that competency in Neuroimaging be tested.

- Resources for evaluation could include competency tests established in the home institution, performance on RadExam (https://www.acr.org/Lifelong-Learning-and-CME/LearningActivities/RadExam), or similar testing formats. Ideally, competency testing should occur at each level of residency either defined by year in residency or number of rotations completed.

- The ASNR has developed milestone recommendations for each level of residency defined either by the year in residency or number of rotations completed (https://www.acgme.org/ Portals/0/PDFs/Milestones/NeuroradiologyMilestones.pdf?ver= 2015-11-06-120525-910).

\section{Resources}

As mentioned above, the ASNR is committed to supporting the education of radiology trainees and provides educational and evaluation resources to help optimize resident education and competency in neuroradiology.

\section{CONCLUSIONS}

From a patient safety perspective, radiology trainees graduating on or after June 2021 and joining practice who have not met the recommendations listed above should seriously consider not interpreting even routine neuroradiology studies.

For the independent practice and interpretation of advanced neuroradiology (including pediatric neuroradiology, head and neck radiology, and advanced neuroimaging), a formal, ACGME-approved neuroradiology fellowship is strongly recommended. A neuroradiology fellowship will ensure exposure, experience, and competency for both routine and advanced neuroradiology. The ACGME requirements for a neuroradiology fellow include the interpretation of 3000 cross-sectional neuro examinations including CTs of the head, neck, and spine; at least 1500 MRIs of the brain, neck, and spine; and at least 250 neurovascular imaging examinations (CTAs and MRAs) (https://www.acgme.org/Portals/0/ PFAssets/ProgramRequirements/423_Neuroradiology_2020. pdf?ver=2020-06-29-164131-690). These numbers are significantly higher than the number of imaging studies required for radiology residents as listed above and are justified for the safe practice of advanced neuroradiology as opposed to routine neuroradiology The Neuroradiology Subspecialty Examination administered by the American Board of Radiology (ABR) allows direct testing of the competencies acquired during a neuroradiology fellowship (https://www.theabr.org/diagnostic-radiology/ subspecialties/neuroradiology).

\section{ACKNOWLEDGMENTS}

These recommendations are endorsed by the following neuroradiology section chiefs: ${ }^{\star}$ Jason W. Allen, MD, PhD, Emory University, ${ }^{\star}$ James Anderson, MD, Oregon Health \& Science University, ${ }^{\star}$ Ari M. Blitz, MD, University Hospitals, Case Western Reserve University School of Medicine, ${ }^{\star}$ Matthew Bobinski, MD, PhD, University of California, Davis, ${ }^{\star}$ Barton F. Branstetter IV, MD, FACR, FSIIM, University of Pittsburgh, ${ }^{*}$ Mauricio Castillo, MD, University of North Carolina, ${ }^{\star}$ Michael Collins, MD, Valleywise Health, ${ }^{\star}$ Nilesh K. Desai, MD, Texas Children’s Hospital, ${ }^{\star}$ Amish Doshi, MD, Mount Sinai Hospital, ${ }^{\star}$ Scott H. Faro, MD, FASFNR, Thomas Jefferson University, ${ }^{\star}$ Girish M Fatterpekar, MD, NYU Grossman School of Medicine, ${ }^{\star}$ Nancy Fischbein, MD, Stanford University, ${ }^{\star}$ Christine Glastonbury, MBBS, University of California, San Francisco, ${ }^{\star}$ Michael F. Goldberg, MD, MPH, Drexel University College of Medicine, ${ }^{\star}$ Ramon Gilberto Gonzalez, MD, $\mathrm{PhD}$, Massachusetts General Hospital and Harvard Medical School, ${ }^{*}$ Michael F. Goldberg, MD, $\mathrm{MPH}$, Drexel University College of Medicine, ${ }^{\star}$ Vivek Gupta, MD, Mayo Clinic Florida, ${ }^{\star}$ Chang Y. Ho, MD, Indiana University, ${ }^{\star}$ Sangam Kanekar, MD, Penn State Milton Hershey Medical Center and Penn State College of Medicine, *Tabassum A. Kennedy, MD, University of WisconsinMadison, ${ }^{\star}$ Claudia Kirsch, MD, Zucker Hofstra School of Medicine at Northwell Health, ${ }^{\star}$ Andrew Klein, MD, Medical College of Wisconsin, ${ }^{\star}$ Roland R. Lee, MD, FACR, University of California, San Diego, ${ }^{\star}$ Ryan K. Lee, MD, MBA, MRMD, Einstein Health Care Network, ${ }^{\star}$ Carlos Leiva Salinas, MD, University of Missouri, ${ }^{\star}$ Laurie A. Loevner, MD, University of Pennsylvania Health System, ${ }^{\star} J o s e p h$ A. Maldjian, MD, UT Southwestern Medical Center, ${ }^{\star}$ Anton Mlikotic, MD, Harbor UCLA Medical Center, ${ }^{\star}$ Franklin G. Moser, MD, MMM, FACR, Cedars-Sinai Medical Center, ${ }^{\star}$ Sugoto Mukherjee, MD, University of Virginia, *Alexander J. Nemeth, MD, FACR, Northwestern University, Feinberg School of Medicine, ${ }^{\star} J o s h u a \mathrm{P}$ Nickerson, MD, Oregon Health \& Science University, ${ }^{\star}$ Diego Nunez, MD, MPH, FACR, Brigham Health and Harvard Medical School, ${ }^{\star}$ Suresh C. Patel, MD, Wayne State University School of Medicine, ${ }^{\star}$ Michael J. Potchen, MD, University of Rochester, ${ }^{\star}$ Prashant Raghavan, MBBS, University of Maryland, ${ }^{\star}$ Karthik Raghuram, MD, UTMB Galveston, ${ }^{\star}$ Dinesh Rao, MD, University of Florida, College of Medicine-Jacksonville, ${ }^{\star}$ Roy F. Riascos, MD, University of Texas Health Houston, ${ }^{\star}$ Caroline Robson, MD, Boston Children's Hospital, ${ }^{\star}$ Jordan Rosenblum, MD, Loyola University Medical Center, ${ }^{\star}$ Jeffrey B. Rykken, MD, University of Minnesota (M-Health), ${ }^{*}$ Gaurav Saigal, MD, University of Miami Miller School of Medicine, ${ }^{\star}$ Noriko Salamon, $\mathrm{MD}, \mathrm{PhD}$, University of California, Los Angeles, ${ }^{\star}$ Osamu Sakai, MD, PhD, FACR, Boton University, ${ }^{\star}$ Karen L. Salzman, MD, University of Utah, *Achint Singh, MD, UT Health San Antonio, ${ }^{\star}$ Aparna Singhal, MD, The University of Alabama at Birmingham, ${ }^{\star}$ Ashok Srinivasan, MD, University of Michigan, ${ }^{\star}$ Maria Vittoria Spampinato, MD, Medical University of South Carolina, ${ }^{\star}$ Jody Tanabe, MD, FASFNR, University of Colorado, *Rudy Vam 
Hemert, MD, University of Arkansas for Medical Sciences, ${ }^{\star}$ Katie D. Vo, MD, Washington University School of Medicine, Mallinckrodt Institute of Radiology, ${ }^{\star}$ Matthew White, MD, University of Nebraska, ${ }^{\star}$ Christopher T. Whitlow, $\mathrm{MD}, \mathrm{PhD}$, Wake Forest University, ${ }^{\star} \mathrm{Max}$ Wintermark, MD, Stanford University, ${ }^{\star}$ Carlos Zamora, MD, University of North Carolina, ${ }^{\star}$ Michael Zeineh, MD, PhD, Stanford University, ${ }^{\star}$ William B. Zucconi, MD, Yale University School of Medicine.
American Society of Neuroradiology (ASNR) Section Chiefs Leadership Group.*

Disclosures: Max Wintermark—UNRELATED: Board Membership: icometrix, EMTensor, Nous. James Anderson-Other Relationships: current member of the Board of the Association of Program Directors in Radiology. Laurie A. LoevnerUNRELATED: Board Membership: ASNR Board of Directors, Co-Chair of the Foundation of the American Society of Neuroradiology; Grants/Grants Pending: Guerbet.* Christine Glastonbury-UNRELATED: Royalties: Elsevier-Amirsys, Comments: not even vaguely related to this work; for writing and editing books. *Money paid to the institution. 